\title{
Use of protein profiles to identify Acinetobacter calcoaceticus in a respiratory care unit
}

\author{
L DIJKSHOORN, * J L WUBBELS, $\dagger$ A J BEUNDERS, $\ddagger$ J E DEGENER, * A L BOKS, * \\ M F MICHEL*
}

\begin{abstract}
From the *Departments of Clinical Microbiology and Infection Control, University Hospital Rotterdam Dijkzigt, Rotterdam and the Departments of $†$ Infection Prevention and $\ddagger$ Medical Microbiology, Ziekenzorg Hospital, Enschede, The Netherlands
\end{abstract}

SUMMARY The presence of acinetobacters in a respiratory care unit was prospectively studied because of an increase in the number of isolations of Acinetobacter calcoaceticus. Cell envelope protein electrophoresis was used to distinguish strains. Eleven protein patterns were observed in isolates from patients and their environment. One pattern (pattern 1) was seen in several patients and environmental samples. Another pattern (pattern 2) was identified repeatedly in samples from skin and mucous membranes of patients in the same ward. After thorough cleaning was undertaken throughout the unit, the pattern 1 strain was no longer cultivated from clinical samples. It is concluded that cell envelope protein electrophoresis is a useful method for tracing epidemic strains of A calcoaceticus.

Various outbreaks of Acinetobacter calcoaceticus in hospitals have been described over the past few years. ${ }^{1-3}$ Any increase in the number of isolations of these bacteria in hospital wards should be acted on quickly. Moreover, a typing method has to be used to determine whether the isolates of an outbreak are identical. Various methods of typing acinetobacters have been described, such as serotyping, ${ }^{4}$ bacteriocin typing, ${ }^{5}$ typing based on protein electrophoretic patterns ${ }^{67}$ and biotyping. ${ }^{8}$

We used cell envelope protein sodium dodecyl sulphate-polyacrylamide gel electrophoresis (SDSPAGE) to investigate an increase in the number of isolations of $\boldsymbol{A}$ calcoaceticus in a respiratory care/ intensive care unit. The analysis of the spread of the bacteria and the origin of the strains were guided by the typing results.

\section{Material and methods}

The study was performed in a respiratory/intensive care unit of a district general hospital with 465 beds. Three beds of the unit are in separate rooms for isolated care; eight other beds are in a large room. This room has an open staff area in its centre and gives open access to a utility room.

Accepted for publication 6 April 1989
ROUTINE MEASURES FOR HYGIENE AND INFECTION CONTROL

Hospital and nursing staff enter the unit through an entrance/dressing room in which clean gowns are put on. Before contact with patients they wash their hands with an ordinary liquid detergent or disinfect them with a solution containing $70 \%$ ethanol. At the beginning of the study the unit was cleaned daily with non-disinfectant cleaning agents. Respiratory tubes were thermally disinfected daily in the hospital's central sterilisation department. After prolonged ventilation the respiratory balloon and accessories were sterilised at a temperature of at least $90^{\circ} \mathrm{C}$. The moisture exchangers (Servo, Siemens-Elema, Stockholm, Sweden) were fitted with a new sponge every day. Bedpans were cleaned using a bedpan rinser.

\section{BACTERIOLOGY}

Prospective samples, specifically analysed for $A$ calcoaceticus, were taken in the unit from patients, nursing staff, and from the environment. The patient samples were taken by means of moist swabs from the following parts of the skin and mucous membranes: scalp, forehead, external auditory canal, nose, throat, armpit, palm, groin, toe web and anus. Single swabs from the throat and anus and imprints of three fingers on blood agar and MacConkey agar (CM7b, Oxoid) were obtained from the nursing staff. Samples from environmental surfaces were taken using contact plates with MacConkey agar. Moist areas were sam- 
Table 1 Samples for prospective investigation of A calcoaceticus

\begin{tabular}{lllll}
\hline & March & & April & \\
\cline { 2 - 5 } & Taken & Positive & Taken & Positive \\
\hline Patients & $168(16)$ & $18(7)$ & $61(17)$ & $25(10)$ \\
Nursing staff & $21(7)$ & None & None & None \\
Inanimate environment & 207 & 32 & None & None \\
\hline
\end{tabular}

pled with swabs. Liquid samples were taken from the staff toilet and from buckets of soapy water intended for cleaning the environment. In one isolation room the bacterial contents of the air were investigated using six settle plates filled with blood agar which were exposed to the air for one and a half hours. Samples were taken from four pieces of respiratory apparatus on the ventilator side of the moisture exchanger.
The swabs and samples of cleaning liquids were shaken in an acetate mineral medium ${ }^{9}$ for enrichment of acinetobacters. The media were incubated overnight at $30^{\circ} \mathrm{C}$ in a shaking water bath and subsequently inoculated on to blood agar and MacConkey agar. Acinetobacters were identified using conventional methods ${ }^{7}$ and differentiated on the basis of the aerobic acidification of glucose.

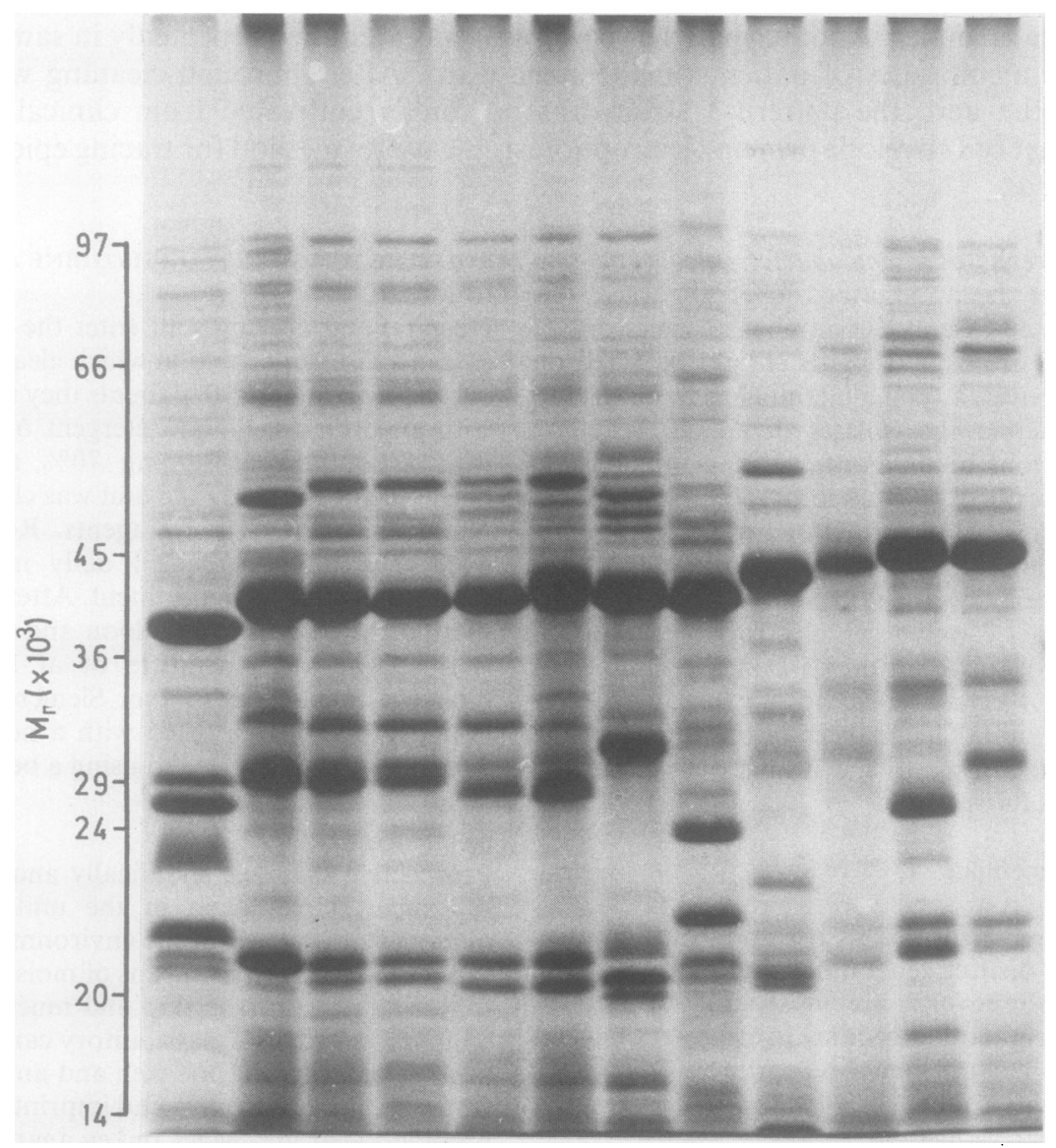

Fig 1 SDS-PAGE patterns of cell envelope proteins of A calcoaceticus from different patients and from environmental sources. $M_{r}=$ relative molecular mass of calibration proteins. 
Table 2 Prevalence of different protein profiles of acinetobacters

\begin{tabular}{|c|c|c|c|}
\hline \multirow[b]{2}{*}{ Pattern } & \multicolumn{2}{|c|}{ Prevalence } & \multirow{2}{*}{$\frac{\text { Environment }}{\text { Samples }}$} \\
\hline & Patients & Samples & \\
\hline $\begin{array}{l}1 \\
2 \\
3,4\end{array}$ & $\begin{array}{r}13 \\
11 \\
1\end{array}$ & $\begin{array}{r}35 \\
26 \\
1\end{array}$ & 13 \\
\hline $\begin{array}{l}5 \\
6,7,8 \\
9 \\
10 \\
11\end{array}$ & 1 & 1 & $\begin{array}{r}1 \\
3 \\
14 \\
1\end{array}$ \\
\hline
\end{tabular}

SDS-PAGE OF CELL ENVELOPE PROTEINS

The method used has been described in detail elsewhere. ${ }^{7}$ Briefly, cell envelope fractions were prepared by ultrasonic disruption of cells followed by differential centrifugation. SDS-PAGE was carried out in a discontinuous system with a stacking and running gel of $3 \%$ and $11 \%$ acrylamide. The protein profiles were inspected visually for similarity or non-similarity. Both the most densely stained band (of relative molecular mass (Mr) $44000-47000$ ) and moderately or weakly stained bands of Mr $18000-92000$ kilos were examined. Profiles were only considered to be identical if no differences were seen in any of the bands.

\section{Results}

Between January and the first week of April 1986 clinical isolates of acinetobacters increased. The bacteria (23 isolates) were cultured from sputum and bronchus secretions from eight of 125 inpatients in the unit and from clinical specimens from seven patients from other wards. Three of these patients had previously been in the intensive care unit for two or three days.

In March acinetobacters were prospectively found on the skin or mucous membranes of seven of 16 patients in the unit (table 1). Cultures from the throat, rectum, and fingers of the nursing staff were negative. Thirty two of 207 environmental samples were positive for acinetobacter. In April skin and mucous membranes of 10 patients in the unit were positive for $A$ calcoaceticus.

\section{SDS-PAGE PATTERNS}

Profiles were classified on the basis of differences between the most densely stained band $(\mathrm{Mr} 40000$ 47000 ) and other bands (Mr $18000-92000)$. Eleven patterns were seen in the 23 Acinetobacter species isolates obtained from the routine laboratory and in the 75 isolates from prospective samples (fig 1). Table 2 gives the prevalence of the patterns. Patterns which were seen only in single isolates or in bacteria from the inanimate environment were not regarded as epidemiologically relevant. On the other hand, pattern 1 was observed in 13 patients and in environmental samples. Pattern 2 was observed in 11 patients. Acinetobacters of pattern 1 and 2 were of the glucoseacidifying variety, with the exception of one isolate.
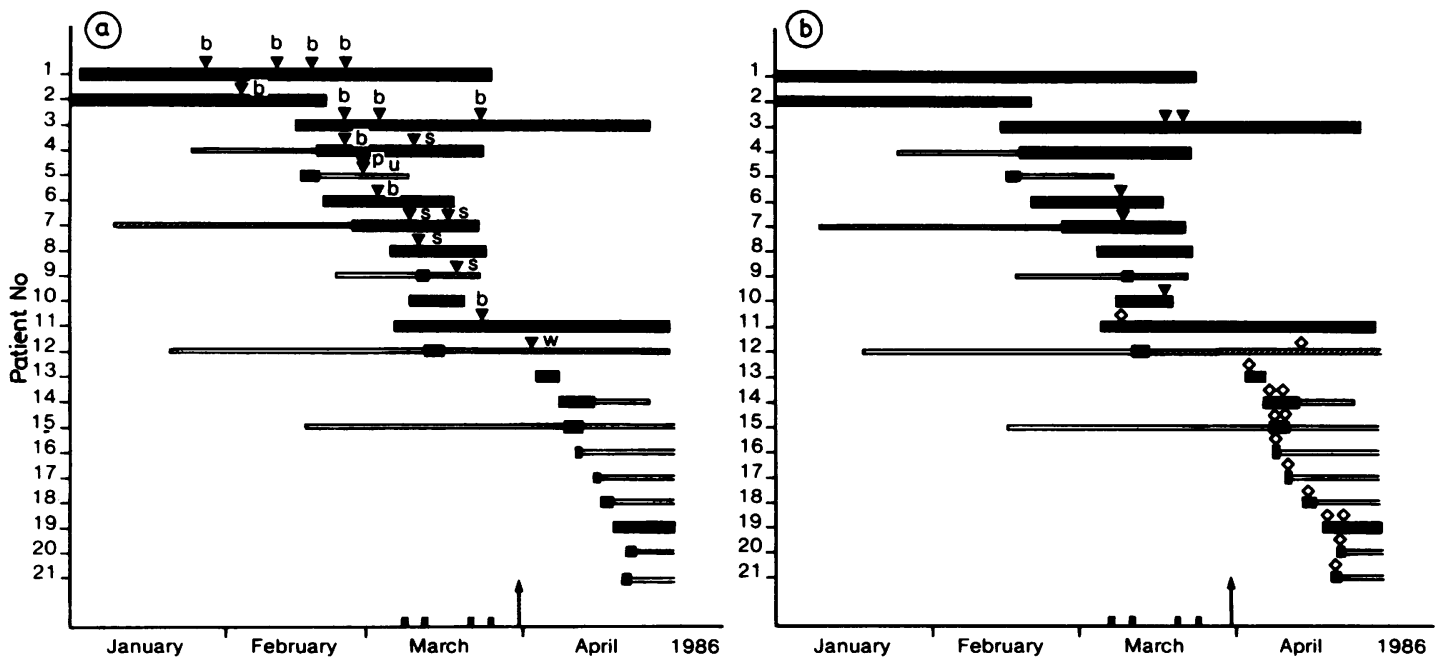

Fig 2 Isolates of Acinetobacter from patients: (a) isolates from samples studied routinely; (b) isolates from prospective samples from skin and mucous membranes. $\nabla=$ pattern $1 ; \diamond=$ pattern $2 . b=$ bronchial secretion; $s=s p u t u m ; p=p u s ;$ $w=$ wound. $\square=I C U ; \square=$ general surgery;,$\square=$ other departments; $\mathbf{D}=$ sampling of the environment; $\uparrow=$ disinfection of $\mathrm{ICU}$. 


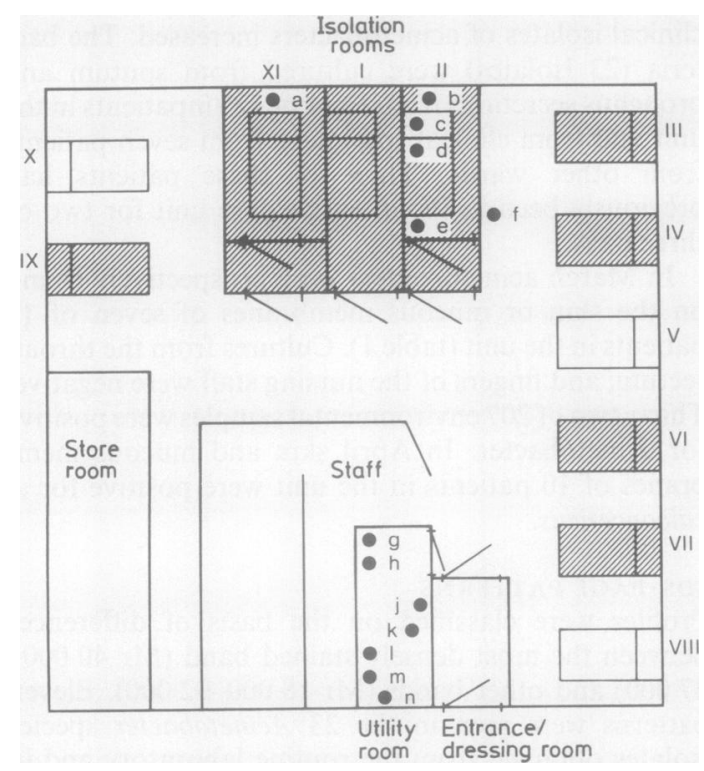

Fig 3 Sites in the inanimate environment from which acinetobacters of pattern 1 were cultivated. $=$ site of isolation; a-d = moisture and external parts of respiratory apparatus; $e=$ cleaning cloth; $f=$ built-in cupboard; $g=$ tuft of fabric; $h, j=$ floor; $k, l=$ draining board; $m=$ bedclothes; $n=$ slop basin. $=$ bed or room with $a$ patient positive for acinetobacter.

\section{SAMPLES FROM PATIENTS IN THE UNIT}

Bacteria of pattern 1 were successively found in clinical samples from 12 patients in the unit (fig 2a). In three patients the bacteria were found only after the patients had left the unit. Positive samples came from the respiratory tract $(n=16)$, from urine, pus, and wound material $(n=3)$. In four patients (fig $2 b)$ acinetobacters of pattern 1 were observed in the following 15 prospective specimens from throat $(n=4)$, forehead $(n=3)$, nose $(n=2)$, groin $(n=2)$, scalp $(n=1)$, armpit $(n=1)$, hand $(n=1)$ and anus $(n=1)$. In April acinetobacters of a different pattern (pattern 2) were found in 10 patients (fig $2 b)$. These bacteria were either simultaneously or successively cultivated from mouth and anus (11 samples of each), and in nose, armpit, anus and toe web (one sample of each).

\section{ENVIRONMENTAL SAMPLES}

The 207 environmental samples were taken from various sites of the unit-for example, from the large nursing room-in the vicinity of infected patients (72 samples), from the utility room (66 samples), from isolation room No II (43 samples), and from respiratory equipment (20 samples). Pattern 1 was observed in 13 of 32 samples from which acinetobac- ters were recovered. These samples were from both dry and moist sites (fig 3). No acinetobacters were grown on settle plates from isolation room No II, nor were they cultivated from the sample places of the respiratory equipment.

\section{CLINICAL ASPECTS AND INTERVENTION}

MEASURES

The 12 unit patients from whom acinetobacters of pattern 1 were isolated had serious disorders of different kinds. Eleven patients were receiving assisted ventilation. The time spent in the unit before the first positive acinetobacter culture ranged from one to 60 days, with a mean of 13 days. There were no indications that acquisition of acinetobacters influenced the course of the illness.

Several measures were taken to control the spread of acinetobacters. Compliance with the regulations on hand hygiene was emphasised. In March a switch was made to the use of a phenolic solution for routine cleaning of the environment. By the end of March the unit was systematically disinfected with this solution. No further acinetobacters were isolated from clinical samples.

\section{Discussion}

Acinetobacters can cause serious infections in susceptible patients ${ }^{10}$ and can become epidemic in hospitals. Environmental spread has been suspected in several reports..$^{13}$ Studies of outbreaks have to be supported by typing data of the strains because acinetobacters are ubiquitous.

In this study the increased presence of acinetobacters seemed to be associated with colonisation rather than with clinical infections, but the increase was regarded as a threat to patients and investigated accordingly. On the basis of our findings, contamination of patients from the environment was conceivable. The intensive cleaning and disinfection of the unit and other hygienic measures may have contributed to the disappearance of acinetobacters of pattern 1 from clinical samples by the end of March. By April, samples from skin and mucous membranes of patients were positive for acinetobacters of a different pattern (pattern 2). Although not noticed in clinical samples by routine analysis, the presence of these acinetobacters on the skin and mucous membranes of patients should be a cause of concern.

The genus Acinetobacter has been divided into 12 genospecies. ${ }^{11}$ The methods for identification of these genospecies and biotyping of genospecies Acinetobacter baumannii ${ }^{2}$ are not yet widely used. In this study the bacteria were identified as Acinetobacter calcoaceticus in sensu lato. Both our findings and those from a previous study' indicate that SDS-PAGE 
protein profile typing is a useful method for the relative comparison of strains in small scale epidemiological surveys. Nothing is as yet known about the distribution of patterns in a wide geographic area. The emergence of acinetobacters as a hospital pathogen has created a need for a general classification system. Combined research on strains by means of recent methods such as identification of genospecies ${ }^{11}$ biotyping, ${ }^{812}$ and SDS-PAGE typing could contribute to the development of such a system.

The study was financed by the 'Praeventiefonds' of the Netherlands, grant No 28-1070. We thank Miss C Rijnsburger and $\mathrm{Mr}$ W van Vianen for analytical assistance and Mrs P Jansen for typing the manuscript.

\section{References}

1 Allen KD, Green HT. Hospital outbreak of multi-resistant Acinetobacter anitratus: an airborne mode of spread? $J$ Hosp Infect 1987;9:110-9.

2 Gerner-Smidt P, Hansen L, Knudsen A, Siboni K, S $\phi$ gaard I. Epidemic spread of Acinetobacter calcoaceticus in a neurosurgical department analyzed by electronic data processing. $J$ Hosp Infect 1985;6:166-74.

3 Stone JW, Das BC. Investigation of an outbreak of infection with Acinetobacter calcoaceticus in a special care baby unit. $J$ Hosp Infect 1985;6:42-8.
4 Das BC, Ayliffe GAJ. Serotyping of Acinetobacter calcoaceticus. J Clin Pathol 1984;37:1388-91.

5 Andrews HJ. Acinetobacter bacteriocin typing. Acinetobacter. J Hosp Infect 1986;7:169-75.

6 Alexander M, Ismail F, Jackman PJH, Noble WC. Fingerprinting Acinetobacter strains from clinical sources by numerical analysis of electrophoretic protein patterns. J Med Microbiol 1984;18:55-64.

7 Dijkshoorn L, Michel MF, Degener JE. Cell envelope protein profiles of Acinetobacter calcoaceticus strains isolated in hospitals. J Med Microbiol 1987;23:313-9.

8 Towner KJ, Chopade BA. Biotyping of Acinetobacter calcoaceticus using the API $20 \mathrm{NE}$ system. J Hosp Infect 1987;10:145-51.

9 Dijkshoorn L, van Vianen W, Degener JE, Michel MF. Typing of Acinetobacter calcoaceticus strains isolated from hospital patients by cell envelope protein profiles. Epidemiol Infect 1987;99:659-67.

10 Glew RH, Moellering RC, Kunz LJ. Infections with Acinetobacter calcoaceticus (Herellea vaginicola): clinical and laboratory studies. Medicine 1977;56:79-97.

11 Bouvet PJM, Grimont PAD. Taxonomy of the genus Acinetobacter with the recognition of Acinetobacter baumannii sp. nov. Acinetobacter haemolyticus sp. nov., Acinetobacter johnsonii sp. nov., and Acinetobacter junii sp. nov. and emended descriptions of Acinetobacter calcoaceticus and Acinetobacter lwoffii. Int J Syst Bacteriol 1986;36:228-40.

12 Bouvet PJM, Grimont PAD. Identification and biotyping of clinical isolates of Acinetobacter. Ann Inst Pasteur Microbiol 1987;138:569-78.

Requests for reprints to: Dr L Dijkshoorn, Department of Clinical Microbiology, University Hospital Rotterdam Dijkzigt, Dr Molewaterplein 40, 3015GD Rotterdam, The Netherlands. 